\title{
The effects of practice on object-based, location-based, and static-display inhibition of return
}

\author{
BRUCE WEAVER, JUAN LUPIÁÑEZ, and FRANCES L. WATSON \\ University of Wales, Bangor, Wales
}

\begin{abstract}
We report two experiments that examine the effects of practice on object-based, location-based, and static-display inhibition of return (IOR). The results are clear: All three effects get smaller with practice. These findings are at odds with the results of Müller and von Mühlenen (1996), who failed to observe object-based IOR and detected no effect of practice on static-display IOR. However, their subjects were more practiced than ours prior to data collection. We suggest, therefore, that the reducing effect of practice on IOR might have occurred in their unrecorded practice sessions. We also discuss a twoprocess model in which IOR is seen as the net effect of underlying inhibitory and excitatory processes. In such models (e.g., Solomon \& Corbit, 1974), practice often results in a reduction of the net effect of the two processes.
\end{abstract}

In what has become a classic chapter, Posner and Cohen (1984) reported the results of a seemingly very simple attentional cuing paradigm. In one version of the task, three horizontally aligned boxes appeared on the screen (see Figure 1A). Either the left or the right peripheral box was then cued by a brief brightening of its outline (Figure 1B). Shortly afterwards, the central box was cued in the same manner (Figure 1C). On some trials, a target appeared in either the left or the right peripheral box (Figure 1D): Half of the targets appeared in the same box as the peripheral cue, and half appeared in the uncued box. The stimulus onset asynchrony (SOA) from peripheral cue to target was either 100 or $650 \mathrm{msec}$. On "catch" trials, no target appeared. The task was to indicate detection of the target by pressing a key as quickly as possible.

The results of this experiment were very clear: Responses to cued targets were faster than responses to uncued targets at the shorter SOA, but were slower at the longer SOA (see Figure 2). Other experiments reported by Posner and Cohen (1984) confirmed this result, and indicated that responding to cued targets is facilitated for about $150 \mathrm{msec}$ after presentation of the cue and impaired for SOAs between 300 and $1,500 \mathrm{msec}$.

Posner, Rafal, Choate, and Vaughan (1985) referred to the slowed responding in the cued condition as inhibition

Some of this research was funded by Grant AP92-24228372 awarded to the second author by the Spanish Ministerio de Educación y Ciencia. We thank Steve Tipper, Ray Klein, Hermann Müller, and an anonymous reviewer for commenting on an earlier draft of this article. Correspondence should be addressed to either B. Weaver or J. Lupiáñez. B. Weaver is now at the Father Sean O'Sullivan Research Centre, 50 Charlton Avenue West, Hamilton, ON, L8N 4A6, Canada (e-mail: bw1960@yahoo. com). J. Lupiáñez is now at Departamento de Psicologia Experimental y Fisiología del Comportamiento, Facultad de Psicología, Campus Universitario de Cartuja, Universidad de Granada, 18071-Granada, Spain (e-mail: jlupiane@platon.ugr.es). of return (IOR). This name for the effect gives a good clue as to Posner and Cohen's (1984) theoretical interpretation of it. They suggested that the peripheral (exogenous) cue at the beginning of the trial effectively captures attention. That is, attention moves to the cued box and is engaged thereupon. When the central cue appears subsequently, attention is disengaged from the peripheral cued box, moved to the central box, and engaged upon it.

If one assumes that the movement of attention takes some time, it is possible to explain the facilitated responding to cued targets at relatively short SOAs as follows: If the SOA is sufficiently short (i.e., $150 \mathrm{msec}$ or less), then attention has not yet had time to disengage and move away from the cued box. Thus, subjects will be quicker to respond to cued targets than to uncued targets.

The impaired responding to cued targets at longer SOAs (i.e., greater than $300 \mathrm{msec}$ ) occurs because, once attention has disengaged and moved away from a particular location, it is inhibited from returning there. ${ }^{1}$ Posner and Cohen (1984) argued that such an inhibitory mechanism could have functional utility because it serves to prevent attentional perseveration and promotes sampling of the whole environment. As such, they suggested that IOR may be a fundamental search mechanism.

IOR is a robust effect, and it has since been replicated many times (e.g., Klein \& Taylor, 1994; Lupiáñez, Milán, Tornay, Madrid, \& Tudela, 1997; Maylor, 1985; Maylor \& Hockey, 1985; Rafal \& Henik, 1994; Tipper, Driver, \& Weaver, 1991). Much of this subsequent research has been directed at figuring out the frame of reference in which IOR operates (Tipper \& Weaver, in press). It was assumed from the beginning that attention was inhibited from returning to the cued location. But was it a location in space or a location on the subject's retina? In short, the general conclusion from this line of research was that the effect is driven by inhibition of a location on a spatiotopic map 
$\mathbf{A}$

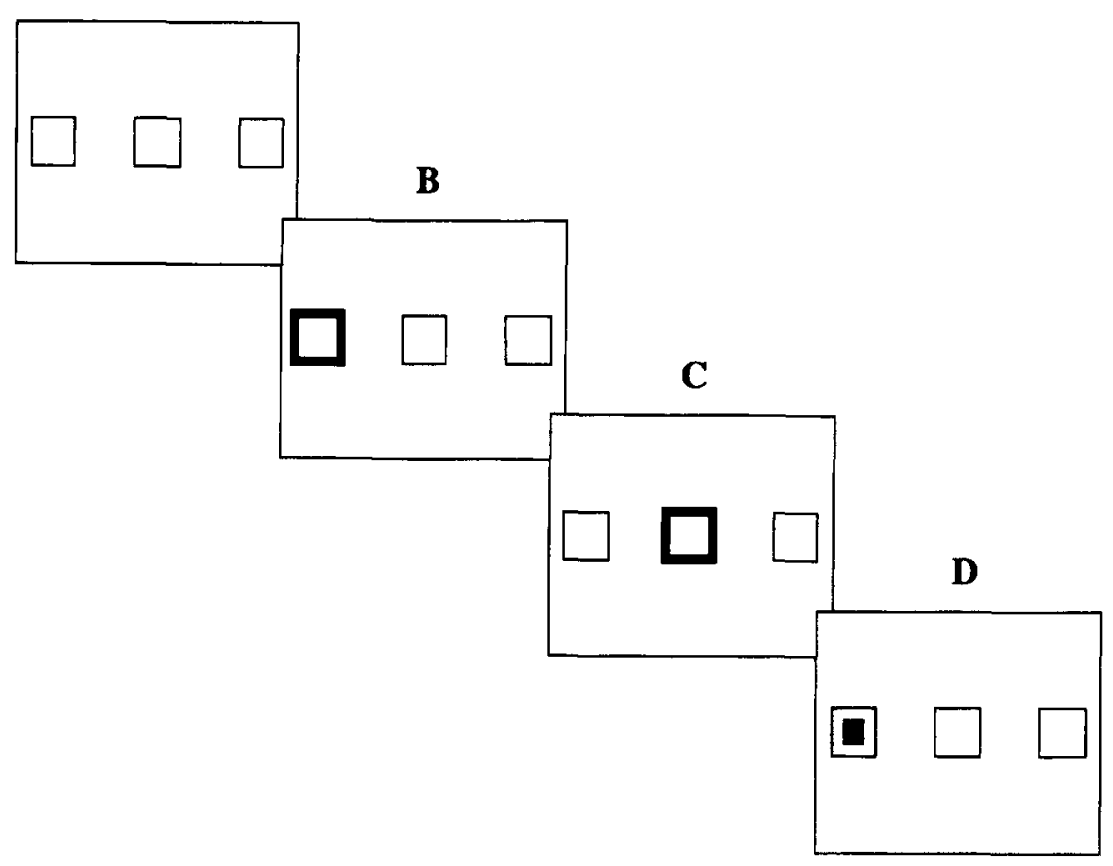

Figure 1. Illustration of the procedure used by Posner and Cohen (1984). Panel D shows a target appearing in the cued box.

rather than a retinotopic map (e.g., Maylor \& Hockey, 1985; Posner \& Cohen, 1984).

An altogether different possibility was put forward, however, by Tipper et al. (1991). They argued that, in the standard paradigm, attention was oriented to (and then withdrawn from) not only a location but also an object. It could be, therefore, that IOR is not a location-based effect at all. It might be an object-based effect-that is, attention might be inhibited from returning to recently attended objects.

In order to explore this possibility, Tipper et al. (1991) rotated the peripheral boxes around the central box in a clockwise direction on a circular arc such that, when the target appeared, the boxes were $90^{\circ}, 180^{\circ}$, or $270^{\circ}$ from their positions at the time of the initial peripheral cue. To begin, let us consider the $90^{\circ}$ condition, which is illustrated in Figure 3. In this condition, when the target appears, the uncued and cued boxes are equidistant from the screen location in which the peripheral cue appeared. If IOR is exclusively location-based, then there ought to be no difference in RTs and error rates between the $90^{\circ}$ cued and uncued conditions. However, Tipper et al. (1991, Experiment 2) observed significantly longer RTs for the cued condition than for the uncued condition.

Skipping the $180^{\circ}$ condition for a moment, let us consider the $270^{\circ}$ rotation condition. As in the $90^{\circ}$ condition, the uncued and cued objects are equidistant from the screen location of the peripheral cue. So, again, if IOR is exclusively location-based, there ought to be no difference between the cued and uncued conditions. Again, however,
Tipper et al. (1991, Experiment 3) observed significantly longer RTs in the cued condition.

Finally, let us consider the $180^{\circ}$ condition. This condition is interesting because it opposes location-based and object-based effects. The cued object moves around and occupies an uncued location; the uncued object moves into the screen location of the initial peripheral cue. So, in this case, if IOR is exclusively location-based, one ought to see faster responding to targets in the cued box (uncued location) than to those in the uncued box (cued location). However, Tipper et al. (1991, Experiments 2 and 3) observed significantly longer RTs for targets in the cued object than for those in the uncued object.

Tipper et al. (1991) failed to detect any significant decrease in the size of the object-based IOR effect at $180^{\circ}$ relative to that at $90^{\circ}$ and $270^{\circ}$. Such a decrease might have been expected if IOR can operate in both location-based and object-based coordinates. In subsequent experiments, however, Tipper, Weaver, Jerreat, and Burak (1994) did find that, while the $90^{\circ}$ condition continued to produce significant object-based IOR, the $180^{\circ}$ condition produced a mixed bag of results: sometimes object-based IOR (but smaller than at $90^{\circ}$ ), sometimes no significant difference between uncued and cued, and sometimes a small but significant location-based IOR effect. These findings suggested quite strongly that IOR can operate in both locationbased and object-based frames of reference.

Tipper et al. (1994) examined this possibility more directly by modifying the experimental paradigm as follows: They increased the number of peripheral boxes from two 


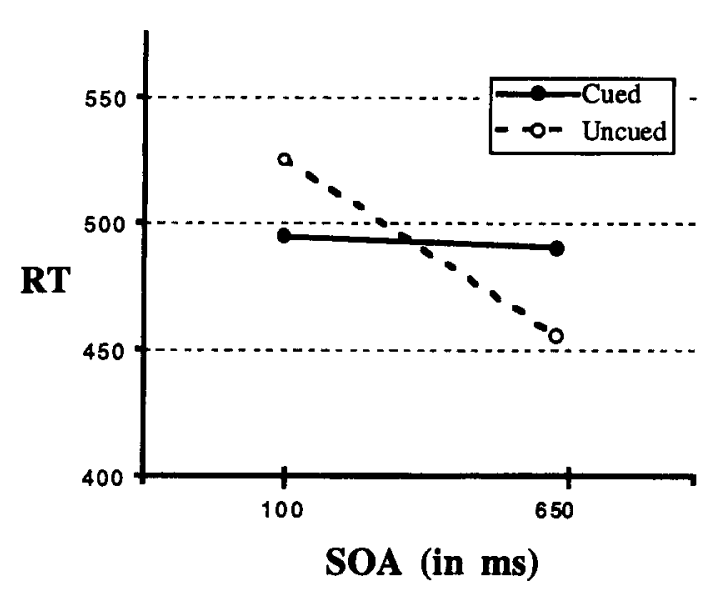

Figure 2. Response time data from a simple experiment reported by Posner and Cohen (1984). The slowed responding to cued targets at the longer SOA is called inhibition of return.

to four. At the start of each trial, one of the four peripheral boxes was cued, then the central box was cued. Rotation of the peripheral boxes began simultaneously with the onset of the central cue and stopped after $90^{\circ}$. At this point, a target could appear in one of the four peripheral boxes: the same object that had been cued (OBJ condition), which now occupied a new location; the same screen location as the cue (LOC condition), which was now occupied by a new object; or one of the two uncued boxes/ locations. The results of this experiment showed no significant difference in response time (RT) between the two uncued conditions; however, both OBJ and LOC conditions had significantly longer RTs than the uncued conditions. In other words, this experiment provided the first direct evidence that IOR can operate in both locationbased and object-based frames of reference.

Object-based IOR has been replicated at least twice in complete independence of Tipper and his colleagues. In a procedure similar to that used by Tipper et al. (1991), Abrams and Dobkin (1994) observed the effect using latency to initiate an eye movement as the dependent measure (rather than keypress latency in a simple detection task). Ro and Rafal (in press) observed object-based IOR in boxes that moved horizontally across the screen. The work of Gibson and Egeth (1994) is also worth mentioning here: They showed IOR to a location within a rotating object (as opposed to a location on the computer screen). This finding supports the general notion that inhibitory mechanisms of attention can have access to object-based frames of reference (see Tipper \& Weaver, in press, for further and more general discussion of how attention can gain access to object-based frames of reference).

Not all attempts to replicate object-based IOR have been successful, however. Müller and von Mühlenen (1996) reported a series of seven experiments (some with multiple parts) in which they found evidence that attention tracks dynamic objects that move from left to right (irrespective of which object was cued); however, they failed to find even a shred of evidence for object-based IOR. They concluded that their experiments "cast doubt on the generality, if not the functional significance, of dynamic object-centred IOR, which is supposed to move with the previously attended object" (p. 247).

The Müller and von Mühlenen (1996) article appears to have convinced at least some readers that object-based IOR is no longer worthy of further study. For example, an anonymous reviewer of a grant application submitted by Steve Tipper (personal communication, July 1996) made these comments:

I cannot offer support for the proposed research because I feel the effort will be mis-placed [sic]. Recently, Müller and Mühlenen (in press) [i.e., Müller \& von Mühlenen, 1996] published a careful and extensive study of both static and moving inhibition of return effects. Having read that paper I am now convinced that these effects are not as informative about basic perceptual processes as I once did. In addition, and regardless of the optimistic tone of the present proposal, the evidence for dynamic object-based inhibition of return appears to be both scant and fragile.

Needless to say, we believe, and hope to convince others, that this sort of reaction to Müller and von Mühlenen's paper is unwarranted.

One important fact about the Müller and von Mühlenen (1996) article may have been overlooked by this anonymous reviewer (and possibly by other readers): In the General Discussion of their paper, Müller and von Mühlenen reported that they did observe object-based IOR when they used the paradigm to be described later in this article (see pp. 246-247 of their article). As they emphasized, however, object-based IOR was seen only in subjects who were inexperienced with visual detection tasks. Müller and von Mühlenen went on to say,

If confirmed, practice effects such as these would argue that object-centred IOR in dynamic displays is strategic (i.e., nonautomatic) in nature, perhaps involving the development of object attributions. This is in contrast to the cuing effects in static displays. .. which, in the present experiments [i.e., their experiments] proved to be robust across many thousands of trials - suggesting that the underlying mechanisms are invoked automatically. (p. 246)

We have two concerns about this conclusion. First, we are not convinced that IOR in static displays is unaffected by practice. Müller and von Mühlenen's (1996) data fail to convince us, because subjects in their experiments were always "familiarized with the task in a session of unrecorded practice trials (on the day preceding the actual experiment)" (p. 246). It may be, therefore, that the effect of practice occurred before data collection began. Müller and von Mühlenen themselves acknowledged this possibility. Note as well that the size of their static IOR effects is consistent with this hypothesis. Whereas it is common to see static IOR effects of $-40 \mathrm{msec}$ or more (e.g., Lupiáñez, Milán, et al., 1997; Tipper et al., 1991), Müller and von Mühlenen's static effects were smaller than $-20 \mathrm{msec}$. 
$\mathbf{A}$

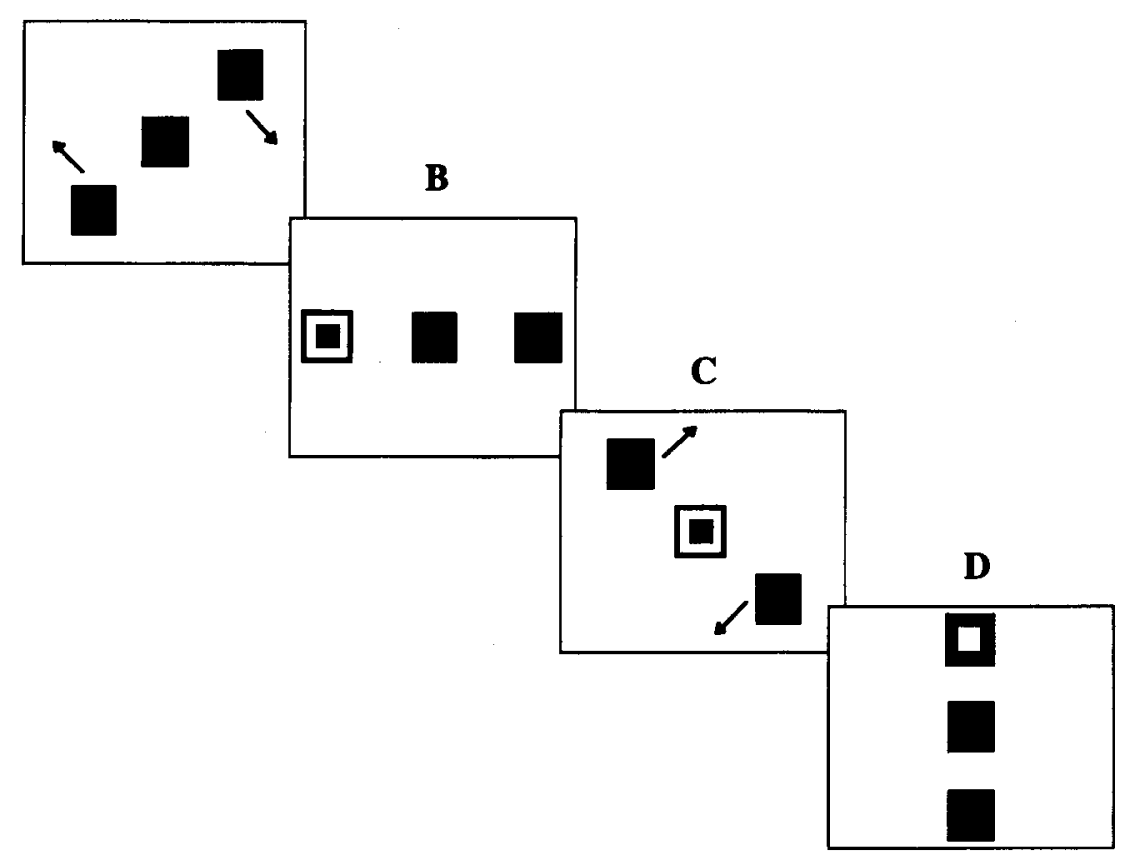

Figure 3. Illustration of the procedure used by Tipper, Driver, and Weaver (1991). Initially, the left and right boxes were misaligned from horizontal (Panel $A$ ). The arrows (which did not appear in the display) indicate that the peripheral boxes rotated around the central box in a clockwise direction. When the boxes were horizontally aligned, motion stopped briefly, and one of the peripheral boxes was cued for $100 \mathrm{msec}$ (Panel B). Two hundred milliseconds after onset of the peripheral cue, the central box was cued and motion of the peripheral boxes resumed (Panel C). After either $90^{\circ}$ or $180^{\circ}$ of rotation from horizontal alignment, a target could appear in either the cued or uncued peripheral object. Panel D shows a target in the cued object after $90^{\circ}$ of rotation. (Note that this figure provides a more accurate representation of the target stimulus than was shown in Figure 1 of the original paper.)

Second, we do not understand how the reduction of object-based IOR with practice supports the notion that it is strategic rather than automatic. It is well known that repeated presentation of a stimulus that elicits a responsesuch as a peripheral cue in an IOR experiment - can lead to either increased or decreased responsivity. Increased responsivity is called sensitization, and decreased responsivity is called habituation. Habituation and sensitization effects are both thought to be automatic; and, according to Domjan and Burkhard (1993), they are "such fundamental forms of how organisms adjust to the environment that they occur in nearly all species and response systems (for example, Peeke \& Petrinovich, 1984)." Therefore, we do not believe that changes in behavior as a result of practice necessarily indicate that the behavior is strategic rather than automatic.

We do believe that IOR is an attentional effect. In other words, we believe that it depends on subjects' attention being summoned by the peripheral cue. We also suspect that subjects may habituate to the peripheral cue. ${ }^{2}$ If so, then we predict that both location-based and object-based IOR effects in the moving-box paradigm will diminish with practice. Furthermore, because we believe that IOR in static displays reflects both location- and object-based effects, it too should diminish with practice, contrary to the reported findings of Müller and von Mühlenen (1996).

Apart from habituation to the cue, there is another reason to expect IOR effects to become smaller with practice. Tipper et al. (1997) investigated object-based IOR in two split-brain patients. They wished to test the notion that object-based IOR is subserved by cortical mechanisms. If so, they reasoned that, in split-brain patients, inhibition should move with a cued object as long as it stays within a visual hemifield. But when the cued object crosses from one hemifield to the other, the inhibition might be lost. If so, there should be no difference between cued and uncued objects in the between-fields condition. Tipper et al (1997) did observe robust object-based IOR when the cued object rotated through $90^{\circ}$ (within a visual hemifield. However, in the between-fields condition, they observed facilitation for the cued object. (In two control groups, object-based IOR was seen for both within- and between-fields movements.)

This facilitation for cued objects led Tipper et al. (1997) to propose that the peripheral cues in IOR experiments have both excitatory and inhibitory effects and that the cuing effect measured in an IOR experiment is really the net effect of these two underlying processes. Under the 
usual circumstances that produce IOR, then, the inhibitory effect must be larger than the excitatory effect.

The idea that observed behavior is the net result of two underlying processes is certainly not new, especially in the field of classical conditioning (e.g., Groves \& Thompson, 1970; Pavlov, 1927; Solomon \& Corbit, 1974; Spence, 1936). Note as well that Posner and Cohen (1984, p. 548) themselves suggested that exogenous cuing effects have two components-one facilitatory and one inhibitoryand that these two components overlap in time (see also Gibson \& Egeth, 1994, and Ro \& Rafal, in press).

A common feature of such two-process (or opponentprocess) models is the idea that the relative strengths of the processes change with practice (e.g., Solomon \& Corbit, 1974). As a result of these changes (which may be entirely automatic rather than strategic), the net effect of the two processes draws closer to a homeostatic baseline. In the present context, this suggests that the relative strengths of the excitatory and inhibitory components proposed to underlie IOR may be brought into closer balance. If so, we expect IOR effects to diminish with practice. (Note that we are using the term IOR purely as a label for the uncued-minus-cued RT difference - that is, IOR refers to the cuing effect, not to the mechanisms that produce the effect.)

In the remainder of this paper, we report two experiments designed to test this prediction about the effects of practice on IOR. The first experiment introduced a new paradigm for observing location-based and object-based IOR that is somewhat simpler than the four-box procedure used by Tipper et al. (1994). At the start of a trial, one of three peripheral boxes was cued, then the central box was cued. As the central cue was presented, the peripheral boxes began to rotate through $120^{\circ}$ around the central box. After the $120^{\circ}$ rotation, a target could appear in one of the three peripheral boxes: the box that was cued initially (OBJ), the box that had rotated into the position of the initial cue (LOC), or the other box (uncued). The subject's task was to press a key as quickly as possible if a target was detected.

The second experiment was like the first, but it used static rather than moving displays. To allow examination of practice effects, subjects in each experiment performed the task four times per day on 3 consecutive days.

\section{EXPERIMENT 1}

We predicted that, initially, subjects would show both location-based and object-based IOR: That is, RTs would be greatest for targets appearing either in the same location on the screen or in the same object as the initial peripheral cue. With increasing practice, however, we expected both of these IOR effects to decrease in size.

\section{Method}

Subjects. Sixteen subjects ( 3 males, 13 females) were recruited from a subject panel set up by the School of Psychology, University of Wales, Bangor. The subjects were naive as to the purpose of the experiment. They ranged in age from 17 to 33, and their mean age was 19.4 years. They were paid $£ 3$ per session for participating.

Apparatus. Stimulus presentation and the recording of RTs and error rates were controlled by an IBM-compatible $486 / 33$ microcomputer with a color video-graphics-array (VGA) monitor. Stimuli were presented in VGA medium-resolution graphics mode, with a $70-\mathrm{Hz}$ refresh rate. Responses were made by pressing microswitches interfaced to the computer via the parallel printer port (see Dalrymple-Alford, 1992). RTs were computed to the nearest millisecond using Bovens and Brysbaert's (1990) TIMEX function.

Procedure. Each trial began with a centrally presented prompt to press the start key when the subject was ready to continue. After the start key was pressed, the screen was cleared, and then four solid boxes appeared on a light gray background. There was a dark gray box in the center of the screen and three colored boxes (blue, red, and magenta) on the perimeter of an imaginary circle around the dark gray box. ${ }^{3}$ At a viewing distance of $55 \mathrm{~cm}$ (from a chinrest), the radius of this circular path was $5.6^{\circ}$ of visual angle. The boxes themselves subtended $0.94^{\circ} \times 1.04^{\circ}$ (horizontal $\times$ vertical).

The initial positioning of the three peripheral boxes was variable and randomly determined, with the constraint that each box was $120^{\circ}$ (in polar coordinates) from the other two. The boxes remained in this initial position for $1,000 \mathrm{msec}$ and then began to rotate (either clockwise or counterclockwise) around the central box. The apparent motion of the peripheral boxes was achieved by presenting a series of frames. The distance between adjacent positions in the series of frames was $7.5^{\circ}$ (in polar coordinates). Thus, 48 frames would be required to show a full $360^{\circ}$ rotation. Generally, each frame remained on for $28.6 \mathrm{msec}$.

After three frames of movement $(1,086 \mathrm{msec}$ after the start of the trial), the motion ceased. One frame $(28.6 \mathrm{msec})$ later, one of the three peripheral boxes was replaced with a cue, such as that shown in Figure 4A. The cue was created by enlarging the colored box to $1.46^{\circ}$ horizontal $\times 1.67^{\circ}$ vertical, then superimposing a smaller white box $\left(1.25^{\circ}\right.$ horizontal $\times 1.46^{\circ}$ vertical $)$, and finally drawing another small colored box $\left(0.52^{\circ} \times 0.63^{\circ}\right)$ in the middle. This peripheral cue remained visible for $86 \mathrm{msec}$, and it was followed by the reappearance of a "normal" colored box.

Two things happened simultaneously $172 \mathrm{msec}$ after the onset of the peripheral cue: The central box was cued for $86 \mathrm{msec}$ in the manner described above, and the apparent motion of the peripheral boxes resumed (Figure 4B). Thus, on each trial, the subject's attention was summoned to one of the three peripheral boxes and then back to the central box.

The apparent motion of the peripheral boxes continued (Figure $4 \mathrm{C}$ ) until they had rotated $120^{\circ}$ around the screen (see Figure 4D). At this point, motion ceased, and, on $60 \%$ of the trials, a probe was presented in one of the peripheral boxes for $57 \mathrm{msec}$ (Figure 4D). The subjects were instructed to press a key as quickly as possible on probe-present trials and to make no response on probe-absent (or "catch") trials. Two types of errors were possible: Either the subjects could fail to respond to a probe (i.e., miss a probe) or they could respond in the absence of a probe (i.e., make a false-alarm response). For probe-present trials, a miss was recorded if no response occurred within $1,200 \mathrm{msec}$ of probe onset. Catch trials ended either $1,200 \mathrm{msec}$ after the point at which a target would have appeared (had there been one) or when a false alarm occurred. Audible feedback (a computer-generated "beep") was given on both types of error trials.

A single run through the experiment consisted of 20 practice trials ( 4 trials per each target-present condition plus 8 catch trials) and 150 test trials ( 30 per target-present condition and 60 catch trials). Short rest breaks $(30 \mathrm{sec}$ ) occurred after 50 and 100 test trials. Each subject completed the experiment four times per day for 3 successive days. Time of day was allowed to vary between subjects, but not within subjects. Within each daily session, the subjects took a short rest break ( $1-2$ min) between runs through the experiment. 


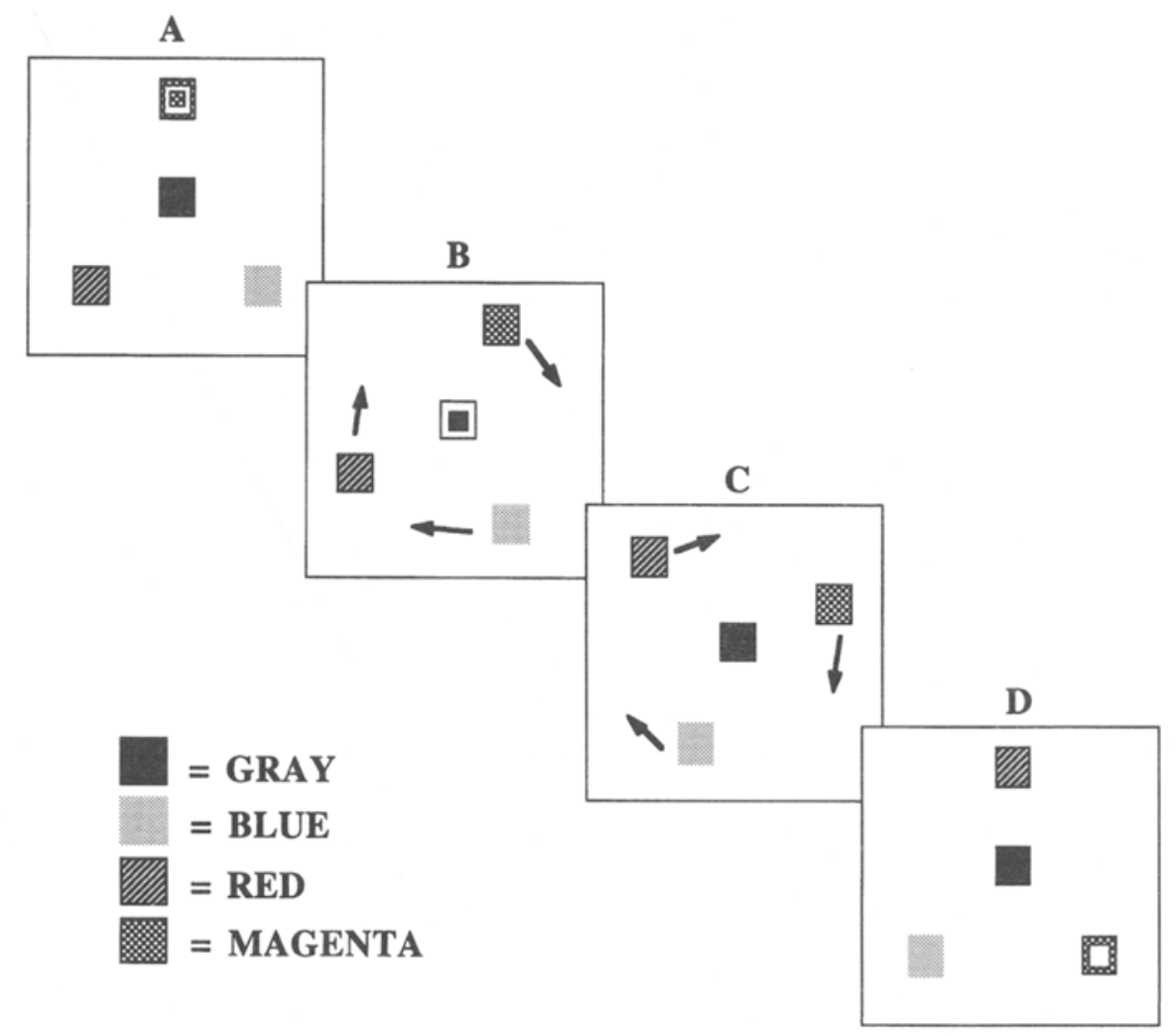

Figure 4. Illustration of the three-box procedure used in Experiment 1.

Design. The experiment had a two-factor repeated measures design. The first factor, cuing, had three levels: In the uncued (baseline) condition, the probe appeared in an uncued object that occupied an uncued location after $120^{\circ}$ of rotation (e.g., the lower left object in Figure 4D). In the location (LOC) condition, the probe appeared in the uncued object that rotated into the cued location (e.g., the upper object in Figure 4D). In the object (OBJ) condition, the probe appeared in the cued object that rotated $120^{\circ}$ away from the cued location (e.g., the lower right object in Figure 4D). The second independent variable, block, had 12 levels: Each subject performed the experiment 12 times.

The dependent measures were median RT for correct responses and percentage of errors.

\section{Results}

Response times. Mean median RTs (for correct trials) and error percentages are shown in Table 1. The RT data were analyzed with a two-factor repeated measures analysis of variance (ANOVA). The two independent variables were block (with 12 levels) and cuing (with levels uncued, LOC, and OBJ). This analysis revealed a significant main effect of block $\left[F(11,165)=14.622, M S_{\mathrm{e}}=2,919.227, p<\right.$ $.0001]$ : With one exception (from Block 10 to Block 11), overall RT decreased in each successive block of trials. The main effect of cuing was also significant $[F(2,30)=8.367$, $\left.M S_{\mathrm{e}}=170.904, p<.005\right]$, but so was the block $\times$ cuing interaction $\left[F(22,330)=2.353, M S_{\mathrm{e}}=75.274, p<.001\right]$.

In order to determine the cause of this interaction, we carried out two separate $12 \times 2$ ANOVAs. The first ex- cluded the OBJ condition and thus examined locationbased IOR (uncued vs. LOC) over 12 blocks. As in the first analysis, the main effect of block was significant $\left[F(11,165)=13.231, M S_{\mathrm{e}}=1,955.617, p<.0001\right]$. The main effect of cuing, or the overall location-based IOR effect, was also significant $\left[F(1,15)=12.846, M S_{\mathrm{e}}=\right.$ $158.488, p<.005]$. Note however, that the block $\times$ cuing interaction was not significant $[F(11,165)=1.610$, $\left.M S_{\mathrm{e}}=60.823, p=.10\right]$.

The second $12 \times 2$ ANOVA examined object-based IOR over 12 blocks by excluding the LOC condition. This analysis revealed significant main effects of block $\left[F(11,165)=15.170, M S_{\mathrm{e}}=1,893.870, p<.0001\right]$ and cuing (i.e., the overall object-based IOR effect) $[F(1,15)=$ $\left.9.050, M S_{\mathrm{e}}=248.844, p<.01\right]$. However, the block $\times$ cuing interaction was also significant $[F(11,165)=3.657$, $\left.M S_{\mathrm{e}}=84.623, p<.0005\right]$.

At first blush, these analyses appear to suggest that Müller and von Mühlenen (1996) were correct: That is, they appear to suggest that, unlike location-based IOR, which persists over thousands of trials of practice, object-based IOR is much more fragile and vanishes with practice. Further inspection of the data, however, reveals that this interpretation is incorrect.

First, note that the nonsignificant interaction of location-based IOR and practice was certainly not resounding in its nonsignificance $(p=.10)$. If anything, this 
Table 1

\begin{tabular}{|c|c|c|c|c|c|c|c|c|c|}
\hline \multirow[b]{2}{*}{ Block } & \multicolumn{3}{|c|}{ Mean Median RT } & \multicolumn{2}{|c|}{$\begin{array}{c}\text { Difference } \\
\text { from uncued }\end{array}$} & \multicolumn{4}{|c|}{ Percent Errors* } \\
\hline & Uncd & LOC & OBJ & LOC & OBJ & Uncd & LOC & $\mathrm{OBJ}$ & Catch \\
\hline 1 & 360 & 375 & 383 & -15 & -23 & 1.2 & 1.2 & 1.7 & 1.9 \\
\hline 2 & 334 & 338 & 342 & -4 & -8 & 0.8 & 0.8 & 1.0 & 2.8 \\
\hline 3 & 321 & 324 & 326 & -3 & -5 & 0.4 & 0.2 & 0.0 & 2.5 \\
\hline 4 & 317 & 323 & 322 & -6 & -5 & 0.4 & 0.6 & 0.2 & 2.4 \\
\hline 5 & 295 & 295 & 298 & 0 & -3 & 0.6 & 0.6 & 0.0 & 2.0 \\
\hline 6 & 288 & 290 & 290 & -2 & -2 & 0.0 & 0.0 & 1.0 & 4.0 \\
\hline 7 & 285 & 290 & 287 & -5 & -2 & 0.0 & 0.0 & 0.2 & 4.2 \\
\hline 8 & 283 & 285 & 282 & -2 & +1 & 0.4 & 0.6 & 0.2 & 3.9 \\
\hline 9 & 280 & 283 & 282 & -3 & -2 & 0.6 & 0.2 & 0.2 & 3.9 \\
\hline 10 & 281 & 282 & 281 & -1 & 0 & 0.4 & 0.4 & 0.4 & 3.4 \\
\hline 11 & 279 & 283 & 281 & -4 & -2 & 0.4 & 0.0 & 0.4 & 2.7 \\
\hline 12 & 272 & 282 & 278 & -10 & -6 & 1.0 & 0.2 & 0.2 & 3.4 \\
\hline
\end{tabular}

*For the Uncd, LOC, and OBJ conditions, errors are misses; for catch trials, they are false alarms.

interaction is probably best described as marginally significant. Therefore, it would be inappropriate to conclude on the basis of these data that location-based IOR does not decrease with practice.

Second, it is clear from the LOC and OBJ scores shown in Table 1 that the interaction of object-based IOR with block was largely, if not entirely, attributable to the presence of a relatively large object-based effect in the first block of trials $(-23 \mathrm{msec})$. In short, the OBJ effect interacted with practice because it was larger than locationbased IOR $(-15 \mathrm{msec})$ in the first place. ${ }^{4}$ After 1 block, the object-based effect came down to the level of the location-based effect and stayed there. Indeed, over the last 11 blocks, with all three cuing conditions included in the analysis, there was no block $\times$ cuing interaction $\left[F(20,300)<1, M S_{\mathrm{e}}=60.509\right]$. Over these 11 blocks, the mean location-based and object-based IOR effects were -4 and $-3 \mathrm{msec}$, respectively. Both of these effects were significant $(p<.05)$ by Fisher's LSD test. ${ }^{5}$

Error percentages. Mean error percentages for all conditions are shown in Table 1. Overall, the error rates were low, indicating that the subjects performed the task very accurately. Note also that, in several cells, the mean was $0 \%$ errors. In these cells, obviously, there was no variance. Therefore, use of a repeated measures ANOVA is not advised. Instead, we used the nonparametric Friedman ANOVA to look at error rates.

We first examined the 36 conditions that fall out of the $12 \times 3$ (block $\times$ cuing) design of the experiment. This analysis revealed no significant differences among the 36 probe-present conditions $\left[\chi^{2}(35, n=16)=17.07\right.$, n.s.]. Analysis of the false-alarm error percentages for the catch trials also revealed no significant differences among the blocks $\left[\chi^{2}(11, n=16)=9.71\right.$, n.s. $]$.

\section{Discussion}

In the preamble to this experiment, we predicted that both location-based and object-based IOR would decrease with practice. The results of the experiment do conform roughly to that prediction. Object-based IOR fell from $-23 \mathrm{msec}$ in Block 1 to an average of $-3 \mathrm{msec}$ over the remaining 11 blocks. Location-based IOR also fell from $-15 \mathrm{msec}$ in Block 1 to an average of $-4 \mathrm{msec}$ over the remaining 11 blocks. The decrease in object-based IOR was statistically significant, but only from the first block to the second. The decrease in location-based IOR was not significant. ${ }^{6}$ To sum up, object-based IOR was initially larger than location-based IOR, but, by Block 2 , it had come down to the size of the location-based effect. Thereafter, neither effect interacted with block, and both were significant.

These results show that, when object-based IOR is contrasted with an unconfounded measure of location-based IOR rather than with the usual static display IOR (which confounds location and object), it is difficult to distinguish between the two on the basis of practice effects. The only hint of a difference in this experiment was that object-based IOR was somewhat larger initially.

Some readers may be surprised at how large the objectbased effect was or, conversely, at how small the locationbased effect was in the first block of trials. In IOR experiments with stationary objects (e.g., Posner \& Cohen, 1984), one typically sees IOR effects in the $-40-\mathrm{msec}$ range. By that standard, the -15 -msec location-based effect reported here is very small indeed. Note, however, that, in our view, IOR measured with stationary objects reflects both object-based and location-based effects. The present experiment, on the other hand, disentangles these two effects and shows that the object-based component is at least as important as the location-based component. Also recall that, with this particular paradigm, it is not unusual for object-based IOR to be larger than location-based IOR (see note 4). Note as well that, for location-based IOR to occur in this paradigm, inhibition must remain associated with a location on the screen that is devoid of any objects for the better part of a half second.

Finally, these results also suggest a possible reason for Müller and von Mühlenen's (1996) failure to detect object- 
Table 2

Mean Median RTs (in Milliseconds) for Correct Responses and Percent Errors for Experiment 2

\begin{tabular}{ccccccc}
\hline & \multicolumn{3}{c}{ Mean Median RT } & & \multicolumn{3}{c}{ Percent Errors* } \\
\cline { 2 - 3 } Block & Uncued & LOC+OBJ & IOR & Uncued & LOC+OBJ & Catch \\
\hline 1 & 313 & 370 & -57 & 2.5 & 2.7 & 1.6 \\
2 & 298 & 330 & -32 & 1.1 & 1.4 & 0.6 \\
3 & 284 & 309 & -25 & 1.0 & 0.8 & 2.3 \\
4 & 276 & 296 & -20 & 1.4 & 1.2 & 1.3 \\
5 & 259 & 282 & -23 & 0.4 & 1.0 & 2.2 \\
6 & 265 & 279 & -14 & 0.4 & 0.6 & 2.0 \\
7 & 266 & 281 & -15 & 0.3 & 1.7 & 3.4 \\
8 & 269 & 283 & -14 & 0.6 & 1.0 & 2.8 \\
9 & 264 & 275 & -11 & 0.6 & 0.4 & 2.1 \\
10 & 262 & 273 & -11 & 0.2 & 0.6 & 2.0 \\
11 & 262 & 270 & -8 & 0.7 & 0.6 & 3.4 \\
12 & 264 & 275 & -11 & 0.6 & 0.4 & 3.0 \\
\hline
\end{tabular}

*For the Uncd, LOC, and OBJ conditions, errors are misses; for catch trials, they are false alarms.

based IOR. You may recall that their subjects were relatively more experienced with the task before data collection began. Note as well that their "experienced" subjects failed to show object-based IOR even in the task reported here (Müller \& von Mühlenen, 1996, p. 246). It is possible, therefore, that object-based IOR in their experiments was already greatly reduced by practice and could not be detected. The maximum number of subjects in Müller and von Mühlenen's experiments with moving boxes was 10 , so their statistical analyses were probably somewhat lacking in power. The present results support this argument. Had we carried out planned comparisons of uncued versus $L O C$ and of uncued versus OBJ in Blocks 2-12, using $t$ tests (with $\alpha_{2 \text {-tailed }}=.05$ ), we would have found significant IOR effects in only four cases: The OBJ effect is significant in Block 2; the LOC effect is significant in Block 4; and both effects are significant in Block 12.7 Clearly, both of these effects can become very difficult to detect after a relatively small amount of practice (e.g., 190 trials prior to the Block 2 test trials).

Of course, it is also possible that object-based IOR either was completely eliminated by practice or never occurred in the first place in Müller and von Mühlenen's (1996) experiments. Further research will be needed to decide this issue conclusively. However, our data indicate that any such research must be concerned with both the effects of practice on object-based IOR and the issue of statistical power.

\section{EXPERIMENT 2}

Experiment 2 was carried out in an effort to determine how IOR in static displays is affected by practice. We used the same three-box paradigm but eliminated motion after the peripheral cue. As noted earlier, we believe that IOR in static displays reflects the joint operation of locationbased and object-based IOR. We predicted, therefore, that IOR in this experiment would be larger initially than either IOR effect seen in Experiment 1, but that this static display IOR effect would also decrease in size with practice.

\section{Method}

Subjects. Sixteen subjects ( 3 males, 13 females) from an introductory course at the Faculty of Psychology of the University of Granada (Spain) participated in this experiment. The subjects were naive as to the purpose of the experiment. Their mean age was 19.2 years (ranging from 17 to 34 ), and they participated to earn course credits.

Apparatus, Procedure, and Design. The apparatus was similar to that used in Experiment 1. The procedure differed from that of Experiment 1 only in that there was no resumption of apparent motion when the central cue appeared: The three peripheral boxes remained stationary after reaching the cuing position. Because of this change, the $\mathrm{OBJ}$ condition of Experiment 1 became a conjoined LOC + OBJ condition, and the LOC condition became a second uncued condition. A preliminary $12 \times 2$ ANOVA on the RT data from the two uncued conditions revealed that there was no difference between them $\left[F(1,15)=0.954, M S_{\mathrm{e}}=169.822\right.$, n.s. $]$. Nor was there an interaction with block $\left[F(11,165)=1.039, M S_{\mathrm{e}}=74.578\right.$, n.s. $]$. For the sake of clarity, therefore, we combined these conditions to form a single uncued condition. Also for the sake of clarity, we shall refer to the cued condition in this experiment as the $\mathrm{LOC}+\mathrm{OBJ}$ condition.

\section{Results}

Response times. Mean median RTs (for correct responses) and error percentages are shown in Table 2. A 12 $\times 2$ repeated measures ANOVA on the median RTs revealed the following: The main effect of block was significant $\left[F(11,165)=23.254, M S_{\mathrm{e}}=740.307, p<.0001\right]$. Mean median RT decreased from one block to the next until Block 5, at which point it stabilized around $269 \pm$ $4 \mathrm{msec}$. The main effect of cuing (uncued vs. LOC + OBJ) was also significant $\left[F(1,15)=21.985, M S_{\mathrm{e}}=1,715.91\right.$, $p<.001]$. Note, however, that the block $\times$ cuing interaction was also significant $\left[F(11,165)=11.073, M S_{\mathrm{e}}=\right.$ $130.755, p<.0001]$. With the exception of a slight hiccup in Block 5 , the size of the IOR effect declined steadily from -57 msec in Block 1 to $-14 \mathrm{msec}$ in Block 6 (see Table 2). Analysis of the data from Blocks 6-12 confirmed that there was no further change in the size of the IOR effect; the block $\times$ cuing interaction was no longer significant $\left[F(6,90)=0.741, M S_{\mathrm{e}}=62.074\right.$, n.s. $]$. The average size of the IOR effect over the final 7 blocks was $-12 \mathrm{msec}$, and this effect was significant $[F(1,15)=$ $\left.13.831, M S_{\mathrm{e}}=569.238, p<.01\right]$. Note as well that overall RT did not change significantly over the last 7 blocks $\left[F(6,90)=1.270, M S_{\mathrm{e}}=311.553, \text { n.s. }\right]^{8}$

Error percentages. Mean error percentages for all conditions are shown in Table 2 . Analysis of the 24 probepresent conditions with a nonparametric Friedman ANOVA was not significant $\left[\chi^{2}(23, n=16)=27.60, \mathrm{n} . \mathrm{s}\right.$. $]$. Analysis of the catch-trial error percentages with the Friedman ANOVA revealed no significant differences among the blocks $\left[\chi^{2}(11, n=16)=13.39\right.$, n.s. $]$.

\section{Discussion}

The important finding in Experiment 2 is that IOR in static displays does get smaller with practice, just like object-based IOR and unconfounded location-based IOR (Experiment 1). Our observation of decreased static display IOR with increasing practice is at odds with the findings of Müller and von Mühlenen (1996). They found no change in 


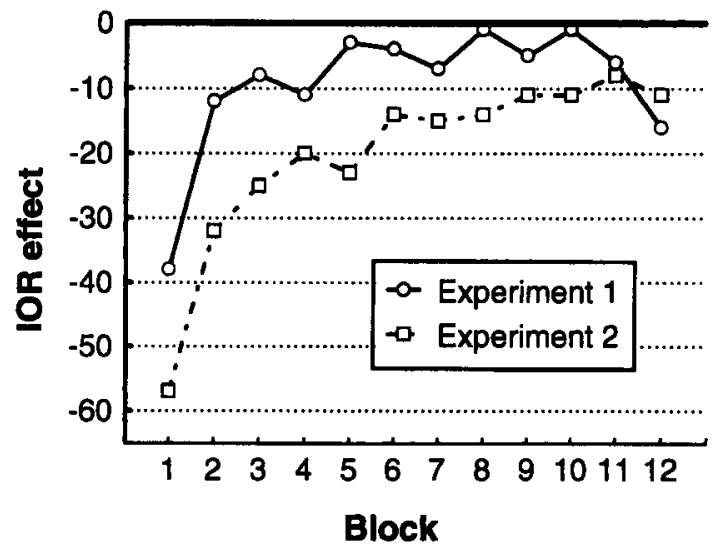

Figure 5. Mean sum of location-based and object-based IOR effects (from Experiment 1), and mean static IOR effect (from Experiment 2) over 12 blocks of practice.

the size of static display IOR over thousands of trials. As noted earlier, however, subjects in their experiments were always well practiced before data collection began. We have already pointed out that Müller and von Mühlenen's effects were much smaller than the usual static IOR effects (e.g., smaller than $-20 \mathrm{msec}$ in their experiments vs. $-57 \mathrm{msec}$ in Block 1 of the present experiment). Note as well that extensive practice does bring static IOR down to the size of effects reported by Müller and von Mühlenen (e.g., -12 msec over the final 7 blocks of the present experiment). We think that it is quite likely, therefore, that practice effects did occur in Müller and von Mühlenen's experiments but were missed because data recording did not begin early enough. Müller and von Mühlenen also acknowledged this possibility, as we indicated earlier.

\section{COMPARISON OF EXPERIMENTS 1 AND 2}

As has been noted here and elsewhere (Tipper \& Weaver, in press), when a stationary paradigm is used to measure IOR, the measured effect may be the sum of both location-based and object-based effects (i.e., LOC + OBJ). From Experiment 1, we concluded that both locationbased and object-based effects decrease with practice. The conclusion drawn from Experiment 2 is that the LOC + OBJ IOR effect also decreases with practice. In order to see whether IOR is affected differently by practice in stationary and moving paradigms, we carried out an analysis comparing the static IOR effect from Experiment 2 with the sum of LOC and OBJ effects from Experiment 1 . The $2 \times 12$ (experiment $\times$ block) mixed ANOVA revealed significant main effects of both experiment $\left[F(1,30)=4.260, M S_{\mathrm{e}}=2,425.7192, p<.05\right]$ and block $\left[F(11,330)=10.353, M S_{\mathrm{e}}=381.8023, p<.0001\right]$. However, the interaction did not reach significance $\left[F(11,330)=1.193, M S_{e}=381.8023\right.$, n.s. $]$.

As can be observed in Figure 5, IOR decreased with practice in both Experiments 1 and 2. It is worth noting here that the decrease in the size of the effect was not significantly different in the moving and stationary displays; the experiment $\times$ block interaction was not significant. The average size of the IOR effect was $-9 \mathrm{msec}$ for Experiment 1 (moving boxes) and $-20 \mathrm{msec}$ for Experiment 2 (static boxes). In retrospect, perhaps it is not surprising that IOR is a bit larger with static displays. It may well be that extra resources needed to process motion, update object files, and so on, cause the effects to be smaller when moving objects are used.

\section{GENERAL DISCUSSION}

The experiments reported herein clearly show that object-based, location-based, and static-display IOR all respond to practice in the same way: They all decrease in size with relatively small amounts of practice (e.g., 190 trials). This does not mean that any or all of these are trivial effects. Nor does it imply that the underlying mechanisms are strategic rather than automatic.

We suggested earlier that IOR may decline because subjects habituate to the uninformative peripheral cue. The present data are not particularly supportive of this hypothesis. If the decline in IOR is due to habituation, then one might expect to see "spontaneous recovery" of the habituated response (see Domjan \& Burkhard, 1982, p. 46): That is, IOR should get smaller across blocks within a day, but it should recover to some extent in the first block of each new day of testing. ${ }^{9}$ No such pattern exists in our data. To our chagrin, however, we must point out that each block of 150 test trials was preceded by 20 unrecorded practice trials. Thus, our data do not provide the strongest possible test of the habituation hypothesis, because any habituation that might have occurred could have been all over within 20 trials. (This illustrates just how important it is to record all trials in experiments that examine attentional effects.) Note as well that if subjects do habituate to the cue, then both early facilitation and IOR ought to become smaller with practice. ${ }^{10}$ We have recently reported data that support this prediction (Lupianez, Weaver, \& Madrid, 1997; abstract available at http: //www.ugr.es/ jlupiane).

As described earlier, we do not envisage IOR as a pure measure of an inhibitory process. Rather we believe that IOR reflects the net effect of inhibitory and excitatory processes set in motion by a peripheral cue (see Tipper et al., 1997). In this theoretical context, the decrease in IOR with practice suggests that the relative strengths of these underlying processes change with practice. By bringing the two processes into closer balance, it is possible to make overall performance less variable and perhaps more efficient therefore.

Admittedly, this two-process model is not currently well developed, and there are some obvious problems that will have to be dealt with. For example, the absence of IOR could be due to the absence of an underlying inhibitory process, or it could be due to the fact that the in- 
hibitory process is counterbalanced by an equally strong excitatory process. If this model is to be taken seriously, it will have to clearly distinguish between these two situations. Perhaps this will be possible through the use of procedures analogous to tests for "conditioned inhibition" in classical conditioning, such as the compound-stimulus test (Pavlov, 1927). ${ }^{11}$

In conclusion, we believe that attentional mechanisms can and do gain access to a variety of frames of reference, including object-based frames (see Tipper \& Weaver, in press). Object-based IOR is just one phenomenon that supports this general view of attention (other evidence comes from research on selective reaching, e.g., Howard \& Tipper, 1997, Meegan \& Tipper, 1998, and Tipper, Lortie, \& Baylis, 1992, and experiments on unilateral neglect, e.g., Behrmann \& Tipper, 1994, and Tipper \& Behrmann, 1996). Our data show that IOR decreases with practice, independent of which frame of reference attention is acting upon. Therefore, we urge any reader who may have dismissed object-based IOR as trivial or insignificant to reconsider that decision in light of these findings.

\section{REFERENCES}

ABrams, R. A., \& DobKin, R. S. (1994). Inhibition of return: Effects of attentional cuing on eye movement latencies. Journal of Experimental Psychology: Human Perception \& Performance, 20, 467-477.

Behrmann, M., \& TiPPER, S. P. (1994). Object based attentional mechanisms: Evidence from patients with unilateral neglect. In L. Umiltà \& M. Moscovitch (Eds.), Attention and performance XIV: Conscious and unconscious processing and cognitive functioning (pp. 351-375). Hillsdale, NJ: Erlbaum.

BOVENS, N., \& BrYSBAERT, M. (1990). IBM PC/XT/AT and PS/2 Turbo Pascal timing with extended resolution. Behavior Research Methods, Instruments, \& Computers, 22, 332-334.

DALRYMPLE-AlFoRD, E. C. (1992). Response-key input via the IBM PC/XT/AT's parallel printer port. Behavior Research Methods, Instruments, \& Computers, 24, 78-79.

Domjan, M., \& Burkhard, B. (1982). The principles of learning and behavior (1 st ed.). Monterey, CA: Brooks/Cole.

DOMJAN, M., \& BuRKhARD, B. (1993). The principles of learning and behavior (3rd ed.). Pacific Grove, CA: Brooks/Cole.

Gibson, B. S., \& EgETH, H. (1994). Inhibition of return to object-based and environment-based locations. Perception \& Psychophysics, 55, 323-339.

Groves, P. M., \& ThOMPSON, R. F. (1970). Habituation: A dual-process theory. Psychological Review, 77, 419-450.

HowARD, L. A., \& TiPPER, S. P. (1997). Hand deviations away from visual cues: Indirect evidence for inhibition. Experimental Brain Research, 113, 144-152.

HowELl, D. C. (1997). Statistical methods for psychology (4th ed.). Belmont, CA: Duxbury .

KLEIN, R. M., \& TAYLOR, T. L. (1994). Categories of cognitive inhibition with reference to attention. In D. Dagenbach $\&$ T. H. Carr (Eds.), Inhibitory processes in attention, memory, and language (pp. 113-150). San Diego: Academic Press.

Lupiáñez, J., Milán, E. G., Tornay, F. J., Madrid, E., \& Tudela, P. (1997). Does IOR occur in discrimination tasks? Yes, it does, but later. Perception \& Psychophysics, 59, 1241-1254.

LuPIÁÑEZ, J., WEAVER, B., \& MADRID, E. (1997, June 26). The effects of practice on exogenous cueing effects. Facilitation and inhibition of return. Paper presented at the UWB Psychology Mini-Conference, School of Psychology, University of Wales, Bangor.

MAYLOR, E. A. (1985). Facilitatory and inhibitory components of orienting in visual space. In M. I. Posner \& O. S. M. Marin (Eds.), Attention and performance XI (pp. 189-207). Hillsdale, NJ: Erlbaum.
MAYLOR, E. A., \& Hockey, R. (1985). Inhibitory component of externally controlled covert orienting in visual space. Journal of Experimental Psychology. Human Perception \& Performance, 11, 777-787.

MEEGAN, D. V., \& TiPPER, S. P. (1998). Reaching into cluttered visual environments: Spatial and temporal influences of distracting objects. Quarterly Journal of Experimental Psychology, 51 A, 225-249.

MülLER, H. J., \& voN MüHLENEN, A. (1996). Attentional tracking and inhibition of return in dynamic displays. Perception \& Psychophysics, 58, 224-249.

PaVLOV, I. P. (1927). Conditioned reflexes (G.V. Anrep, Trans.). London: Oxford University Press.

Peeke, H. V. S., \& Petrinovich, L. (Eds.) (1984). Habituation, sensitization, and behavior. New York: Academic Press.

Posner, M. I., \& CoHEN, Y. (1984). Components of visual orienting. In H. Bouma \& D. G. Bouwhuis (Eds.), Attention and performance $X$ (pp. 531-556). Hillsdale, NJ: Erlbaum.

Posner, M. I., Rafal, R. D., Choate, L. S., \& Vaughan, J. (1985). Inhibition of return: Neural basis and function. Cognitive Neuropsychology, 2, 211-228

Pratt, J., Kingstone, A., \& Khoe, W. (1997). Inhibition of return in location- and identity-based choice decision tasks. Perception \& Psychophysics, 59, 964-971.

Rafal, R. D., \& HeNiK, A. (1994). The neurology of inhibition: Integrating controlled and automatic processes. In D. Dagenbach \& T. H. Carr (Eds.), Inhibitory processes in attention, memory, and language (pp. 1-51). San Diego: Academic Press.

Reuter-Lorenz, P. A., JhA, A., \& Rosenquist, J. N. (1996). What is inhibited in "inhibition of return"? Journal of Experimental Psychology: Human Perception \& Performance, 22, 367-378.

Ro, T., \& RAFAL, R. D. (in press). Apparent motion and attention: An object-based facilitatory component of visual orienting. Perception \& Psychophysics.

Solomon, R. L., \& CoRBIT, J. D. (1974). An opponent-process theory of motivation: I. The temporal dynamics of affect. Psychological Review, 81, 119-145.

SPENCE, K. W. (1936). The nature of discrimination learning in anımals. Psychological Review, 43, 427-449.

TipPer, S. P., \& BehrmanN, M. (1996). Object-centred not scene-based visual neglect. Journal of Experimental Psychology Human Perception \& Performance, 22, 1261-1278.

TIPPER, S. P., DRIVER, J., \& WEAVER, B. (1991). Object-centred inhibition of return of visual attention. Quarterly Journal of Experimental Psychology, 43A, 289-298.

TIPPER, S. P., Jordan, H., \& WEAVER, B. (in press). Scene-based and object-centered inhibition of return: Evidence for dual orienting mechanisms. Perception \& Psychophysics.

TIPPER, S. P., LoRTIE, C., \& BAYLIS, G. C. (1992). Selective reaching: Evidence for action-centered attention. Journal of Experimental Psychology Human Perception \& Performance, 18, 891-905.

TipPer, S. P., Rafal, R., Reuter-LoRenz, P. A., STaRrVeldt, Y., Ro, T., EgLY, R., DANZinger, S., \& WEAVER, B. (1997). Object-based facilitation and inhibition from visual orienting in the human split-brain. Journal of Experimental Psychology: Human Perception \& Performance, 23, 1522-1532.

TIPPER, S. P., \& WeAVER, B. (in press). The medium of attention: Location-based, object-centered or scene-based? In R. Wright (Ed.), Visual attention. Oxford: Oxford University Press.

Tipper, S. P., Weaver, B., Jerreat, L. M., \& Burak, A. L. (1994). Object-based and environment-based inhibition of return of visual attention. Journal of Experimental Psychology: Human Perception \& Performance, 20, 478-499.

\section{NOTES}

1. What exactly gets inhibited in IOR is a matter of some debate (see, e.g., Klein \& Taylor, 1994; Pratt, Kingstone, \& Khoe, 1997; ReuterLorenz, Jha, \& Rosenquist, 1996). Resolution of this debate is not critical to the points we wish to make in this article (viz. that IOR can operate in both location-based and object-based frames of reference, and that object-based, location-based, and static-display IOR effects all decrease with practice). 
2. We predict habituation rather than sensitization because (1) the cue is uninformative, and (2) the size of Müller and von Mühlenen's (1996) static IOR effect is much smaller than usual.

3. We displayed the three peripheral boxes in different colors to promote perception of three distinct objects as opposed to three corners of a single object, for example. Subsequent work in our laboratory has shown that this distinction can be important in such experiments (e.g., Tipper, Jordan, \& Weaver, in press).

4. We have collected data with this paradigm several times at Bangor University, the University of Granada, and McMaster University in Canada. In our experience, object-based IOR is more often than not larger than location-based IOR; but the difference is rarely, if ever, statistically significant.

5. Fisher's LSD test is not recommended for general use because, if the complete null hypothesis (i.e., $\mathrm{H}_{0}$ for the omnibus $F$ test) is not true, it does not provide control over the familywise error rate. However, it is strongly recommended by Howell (1997) when there are only three treatment means, because, in this case, the familywise error rate is controlled. Fisher's LSD test is also more powerful than alternative tests such as Tukey or Newman-Keuls.

6. As was suggested earlier, an experiment with more power would probably detect a significant decline in location-based IOR from Block 1 to Block 2 . Such an outcome would not alter our basic interpretation of the results, and it would in fact support our original predictions.
7. The percentages of subjects showing negative $L O C$ and $O B J$ scores support the conclusions drawn from these $t$ tests. In Block 1, the LOC and OBJ scores were negative for $75 \%$ of subjects each. In the last 11 blocks, the mean percentage of subjects with negative LOC scores ranged from $44 \%$ to $81 \%$, with a mean of $57.4 \%$; the mean percentage of subjects with negative OBJ scores ranged from $31 \%$ to $69 \%$, with a mean of $54.5 \%$. In Block 12, where $t$ tests showed both effects to be significant, the percentages were $81 \%$ for LOC and $69 \%$ for OBJ.

8. In Block $1,93.8 \%$ of subjects had a negative LOC + OBJ score. Over the last 11 blocks, the percentages ranged from $62.5 \%$ and $87.5 \%$, with a mean of $76.7 \%$. In Block $12,75 \%$ of the LOC + OBJ scores were negative.

9. We thank Hermann Müller for raising this possibility.

10. We thank Ray Klein for this suggestion.

11. The compound stimulus test for conditioned inhibition entails the presentation of two conditional stimuli (CSs). Suppose that the first CS elicits a conditional response (CR) when it is presented alone: This stimulus is a CS+. If the second stimulus is a conditioned inhibitor of that response, or a $\mathrm{CS}-$, then when $\mathrm{CS}+$ and $\mathrm{CS}-$ are presented as a compound, the $\mathrm{CR}$ will be suppressed relative to the $\mathrm{CS}+$ alone condition, and the degree of suppression reflects the amount or strength of the conditioned inhibition.

(Manuscript received January 31, 1997; revision accepted for publication July 31,1997 .) 